\title{
Perceived Postgraduate Research Supervisory Practices and Satisfaction towards Supervision among Supervisees at Faculty of Education
}

\author{
Nurhamizah Ishak \\ Academy of Language Studies, \\ Universiti Teknologi MARA Melaka, \\ Melaka, Malaysia \\ hamizahishak@uitm.edu.my
}

\author{
Farah Nadzirah Khairuddin \\ Faculty of Education, \\ Universiti Teknologi MARA Selangor, \\ Selangor, Malaysia \\ farahnadzirah92@gmail.com
}

\author{
Nur Shaziella Aziz \\ Faculty of Education, \\ Universiti Teknologi MARA Selangor, \\ Selangor, Malaysia \\ shaziella@gmail.com
}

\begin{abstract}
Effective supervision received by postgraduate students boosts their motivation to produce a high quality research. This paper looks at the perceived postgraduate research supervisory practices and satisfaction towards supervision among supervisees at Faculty of Education in a Malaysian public university. Data was collected through a questionnaire on the sample of 45 Part 3 full-time Master's degree (Coursework) students. However, only 33 sets of questionnaires were returned to the researchers (response rate=94.3\%). It was found that most supervisees perceived that their dissertation supervisors have continually applied various supervisory practices during the supervision session and they were very satisfied with the supervision that they have received. Furthermore, there was a positive, strong, and significant relationship between the perceived supervisory practices and supervisees' satisfaction. Nevertheless, there were no significant differences between perceived supervisory practices and courses, as well as between perceived supervisory practices and frequency of meeting. As for the implications of this study, it contributes to the corpus of knowledge in the area of postgraduate supervision in local higher education institution context and provides empirical data to assist the Ministry of Education in conducting strategic planning to enhance implementation of effective supervisory practices among postgraduate research supervisors.
\end{abstract}

Keywords: Postgraduate, supervision, Higher Education, Malaysia, supervisory practice, supervisory satisfaction

\section{INTRODUCTION}

Postgraduate research supervision is undeniably a complex two-way interactional process that requires both the student and the supervisor to consciously engage each other within the spirit of professionalism, respect, collegiality, and open-mindedness (Ganqa, 2012). The relationship between the two parties can be seen as a combination of personal and professional relationships 
as both the student and supervisor will be involved together in selecting a research topic, planning the research, identifying and acquiring the necessary resources, managing the project, actively conducting the research, carrying out the literature review, analyzing and interpreting the data collected, writing the thesis, defending it and possibly later publishing it. Furthermore, most supervisors expect their postgraduate students to be diligent, conscientious, enthusiastic, and motivated towards their research works (Ismail, Abiddin \& Hassan, 2011). Supervisees are advised to always keep in touch and have regular meetings with their supervisors; so the supervisors can give feedback constantly and be up-to-date on their research progress.

\section{Problem Statement}

Many postgraduate students have failed to complete their research within the stipulated time frame or have given up conducting their research due to problems related to inadequate supervision. Wichmann-Hansen et al. (2012) stated that the responsibility for completing a dissertation or thesis within a reasonable time lies on both the postgraduate student and the supervisor. Moreover, the relationship between a supervisor and a postgraduate student has always been considered as a key factor in determining the success or failure of postgraduate students' research work.

According to Abidin, Ismail, and Ismail (2011), supervisors and supervisees must play their roles effectively and maintain active communication throughout the supervision period. Without open and honest communication, it is very difficult for the supervisors to identify the difficulties faced by their supervisees in coping with conducting the research, as well as they are not aware whether the supervisory practices that they apply are effective or not in helping the supervisees to complete the research. Meanwhile, for the supervisees, lack of communication with the supervisors will hinder their comprehension regarding the research direction, and this eventually will cause them to feel frustrated with their research progress. Besides that, both parties should always be level-headed as well as willing to listen to each other and to talk openly whenever they face problems related to the research works during the supervision (Derick et al., 2019).

Most postgraduate programmes include completion of research output in the form of a dissertation or thesis as a compulsory requirement to graduate. Currently, there has been a marked increase of postgraduate students in many public universities each year in Malaysia since 2002 (Kaur \& Sidhu, 2019). This also means an increasing number of supervisees to be supervised. However, the numbers of research on postgraduate supervision in the local setting are still not sufficient as compared to other developed countries. Therefore, to understand the current situation in postgraduate research supervision in Malaysia, this research examined the relationship between perceived postgraduate research supervisory practices and satisfaction towards supervision among supervisees at Faculty of Education in a Malaysian public university. 


\section{Research Questions}

1. What is the level of supervisees' perception towards the supervisory practices of their dissertation supervisor?

2. What is the level of satisfaction of the supervisees towards the supervision that they have received?

3. Is there any significant difference between perceived supervisory practices and courses?

4. Is there any significant difference between perceived supervisory practices and the frequency of meetings?

5. Is there any significant relationship between perceived supervisory practices and supervisees' satisfaction?

\section{LITERATURE REVIEW}

\section{Effective Supervisory Practices}

Supervisory practices refer to the behaviour patterns used by the supervisor for approaching and responding to trainees (Shuss, 2012). Previous researchers have reported that supervisors use various supervisory practices when supervising their supervisees' research projects. The types of supervisory practices applied by the supervisors will eventually influence the supervisee's learning experience, the types of feedback supervisees will receive, and the supervisees' satisfaction with the supervisory process (Chiapetta-Swanson, 2011).

There are diverse opinions regarding effective supervisory practices. One of them is the supervisors should give constant support and reassurance to the supervisees in order to maintain their high motivation to accomplish the research. According to Amzat, Ismail \& Kayodea (2011), the supervisors also need to be sensitive to students' time and competence limitations, as well as be ready to assist them in overcoming these limitations. Effective supervisory practices are also typically related to useful advice and constructive feedback. Advice is usually given during the initial planning of the research especially in terms of research direction, topic selection, and feasibility of the research. Meanwhile, feedback is given on the progress of the supervisee's research drafts especially in terms of clarity of the employed research methodology, coherence of the data analysis, rigorousness of the literature review, and consistency of their academic writing style (Abiddin, Ismail \& Ismail, 2011). Hence, supervisors should read the student's written work thoroughly and provides constructive feedback; yet, the reality indicates the opposite situation. One of the most common students' complaints is that supervisors have been unduly slow in reading research drafts (Mohd Tahir et al., 2012). Certain supervisors give vague feedback about the research drafts which caused difficulty and confusion to the students to make corrections on the drafts.

Next, supervisors are encouraged to adopt flexible supervision strategies depending on the attributes of the particular student (Derick et al., 2019). Postgraduate students are not homogenous; instead, they are highly diverse in terms of academic ability, personality attributes, motivation, and attitude. Thus, if the supervisors apply the same supervisory 
strategies on all supervisees, it is highly likely that the effectiveness of supervision will vary from one supervisee to another supervisee.

\section{Satisfaction with Supervision}

Satisfaction has been defined as the "desired outcome of a task or job that enhances a person's self-esteem" (Athiyaman, 1997). In the education setting, satisfaction plays a major role in student development. It has been shown that a good environment that facilitates learning and growth will result in a more motivated student. Therefore, the more satisfied students are with their educational experience, the more likely they are to put forth the necessary efforts to succeed.

Student satisfaction with supervision is influenced by various aspects of the supervision process. Negative experiences such as communications problems and personality conflicts between supervisor and supervisee that occur during supervision are counterproductive to the supervision and learning processes. Previous researchers found that the students who reported negative events during supervision were more likely to report lower levels of satisfaction with their supervisor compared to students who did not experience negative events (Del Rio et al., 2017). Therefore, it can be concluded that student dissatisfaction with supervision was a likely outcome when a negative event occurred.

\section{Supervision Model}

This study employed Palomo, Beinart, and Cooper's bi-directional supervisory relationship model (2010) that comprises six components (refer to Figure 1). The first component is a safe base. This component refers to a collaborative environment during supervision in which supervisees feel comfortable to exchange opinions with the supervisors and the supervisor is responsive to supervisees' needs and problems. The second component is structure. It refers to practical boundaries set up and protected by the supervisors with regards to time and structure of supervision sessions such as regular, scheduled in advance, uninterrupted, and not regularly cut short. The third component is commitment, in which the supervisor is interested in and committed to the task of supervision as well as does not see supervisees as a burden. The fourth component is reflective education in which the supervisor facilitates supervisees in understanding the application of theories in real-life context. The fifth component is role models in which supervisors are viewed as experts who possess special knowledge, high credibility, and integrity. The sixth component is formative feedback that entails supervisors giving regular and appropriate feedback on the supervisees' research. 


\section{Figure 1}

Palomo, Beinart and Cooper's Bi-directional Supervisory Relationship Model (2010)

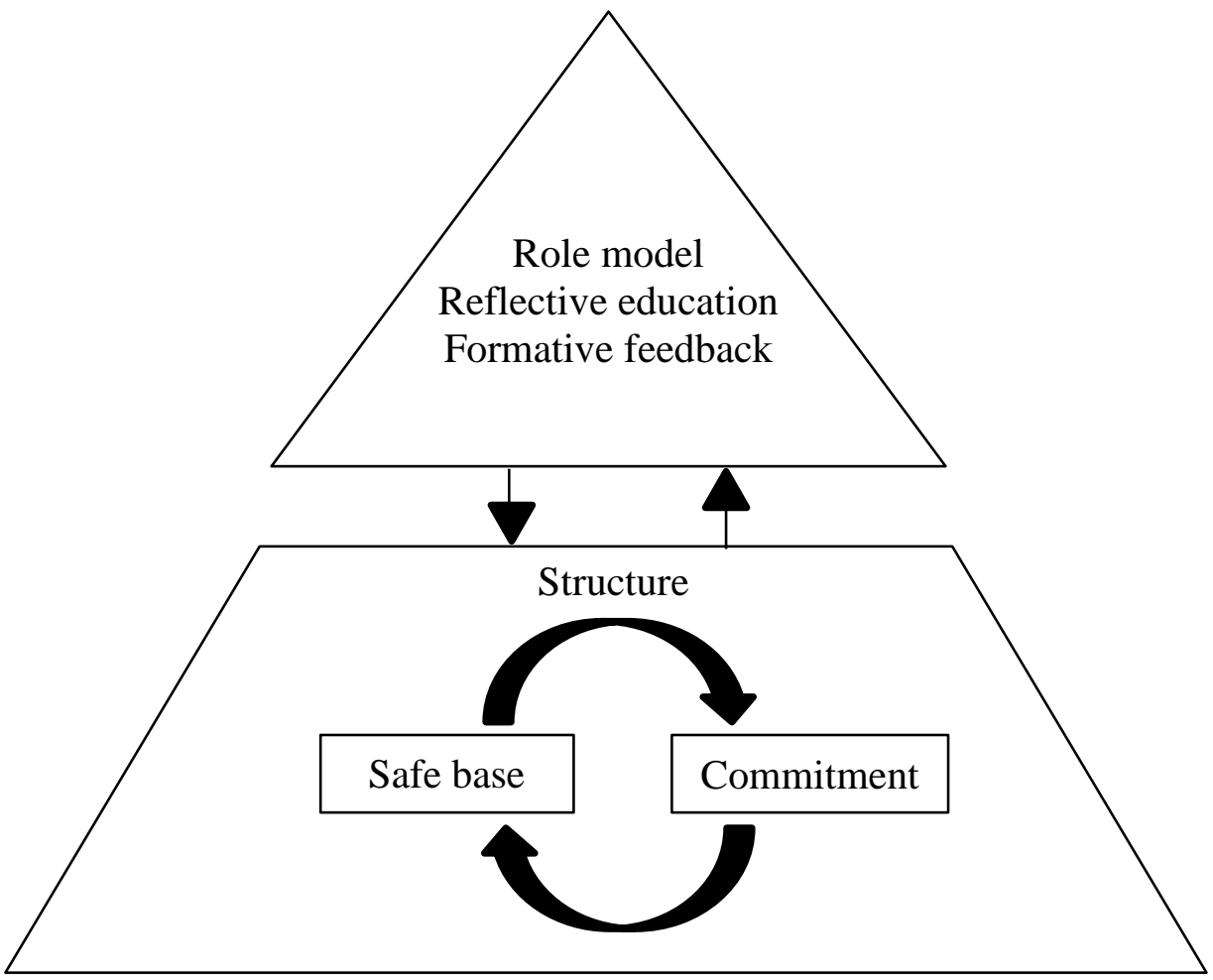

\section{Conceptual Framework}

This study focused on one independent variable of perceived supervisory practices and one dependent variable of supervisees' satisfaction towards the supervision. If supervisors used effective supervisory practices during supervision, it is highly possible that supervisees' satisfaction towards the supervision that they have received might be enhanced (refer to Figure 2).

Figure 2

Conceptual Framework for the Study of the Relationship between Perceived Supervisory Practices and Satisfaction towards Supervision

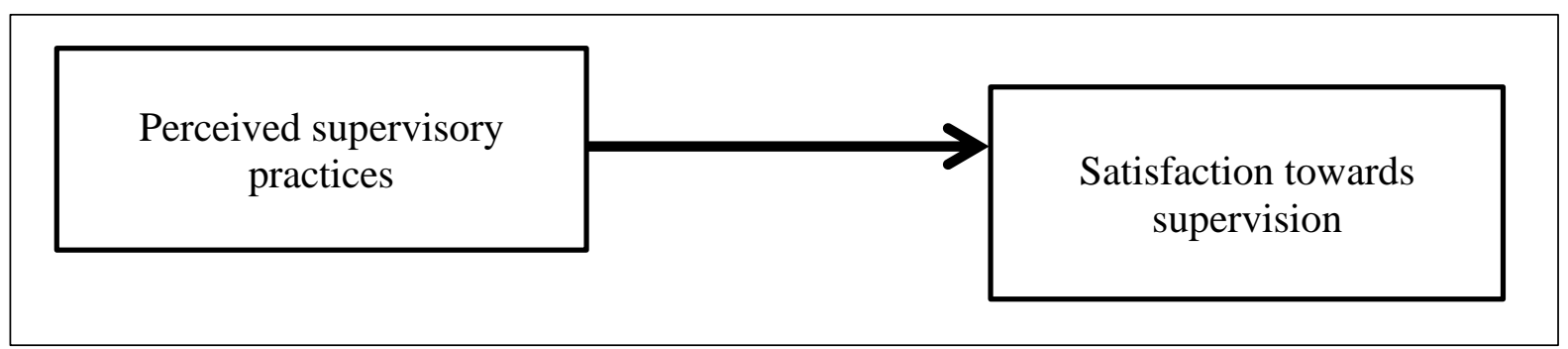




\section{METHODOLOGY}

\section{Research Design}

Research design is determined by the research objective and research questions. This research was descriptive and correlational as it investigated 1) the level of perceived supervisory practices of the supervisors, and 2) the level of satisfaction of the supervisees towards the supervision that they received; as well as examined whether there are any significant differences 3) between perceived supervisory practices and course, and 4) between perceived supervisory practices and frequency of meeting; and 5) examined whether there is any significant relationship between perceived supervisory practices and supervisees' satisfaction. To achieve this purpose, this research employed quantitative research design. Quantitative research is a method used to test objective theories by examining the relationship among variables, which gives more accurate empirical data on the level of perceived supervisory practices of the supervisors and the level of satisfaction of the supervisees towards the supervision that they received.

\section{Population and Sample}

The population of this research was full-time Master's degree students (coursework) at Faculty of Education in a public university in Selangor that comprised 110 students. However, since not all students especially Part 1 and Part 2 have been assigned with supervisors when the research was conducted, only Part 3 full-time Master's degree (Coursework) students were finally chosen as the sample. Hence, the sample size of this research consisted of all 45 Part 3 full-time Master's degree (Coursework) students from different courses in the faculty such as Teaching of English as Second Language (TESL), Visual Art Education, and Education Management and Leadership courses.

\section{Instrumentation}

A questionnaire was the main instrument for this research. The questionnaire was divided into three sections: Section A, Section B, and Open-ended Questions with a total of 44 items.

Section A focused on the demographic data of the respondents. It consisted of four items namely gender, age, course, and frequency of meeting with the supervisor. The respondents were required to tick the information related to them in the boxes provided for items A1 (gender) and A3 (course). Meanwhile, for items A2 (age) and A4 (frequency of meeting), they were required to fill in the information related to them in the spaces provided.

Section B focused on perceived supervisory practice. The items in this section were adapted from the Supervisory Relationship Questionnaire (SRQ), developed by Palamo (2010). The original questionnaire consisted of 67 items. However, 27 items from the original questionnaire were omitted in this section. The modifications on items were done to suit the 
target population, to ensure the clarity and comprehensibility of these items for the respondents, as well as to guarantee that these items gave an accurate reflection of supervisory practices in the faculty. The method of response was a 5-point Likert scale with a scale of 1, 2, 3, 4, and 5, in which 1 indicates "strongly disagree", 2 indicates "disagree", 3 indicates "neutral", 4 indicates "agree", and 5 indicates "strongly disagree".

Open-ended questions were also included in the questionnaire to elaborate responses for closed-ended questions and offer insights on aspects that were not captured in the closed questions. There were two open-ended questions in the questionnaire. The first open-ended question asked for the respondents to rate their level of satisfaction towards the supervision that they have received based on the scale 1 (not very satisfied) to 5 (very satisfied) as well as provide elaboration behind their satisfaction/dissatisfaction rating. The second open-ended question asked for the respondents to state whether they would recommend this supervisor to future supervisees and provide elaboration behind their 'Yes, I recommend' and 'No, I do not recommend' responses.

\section{Data Collection Procedures}

The researchers distributed 45 sets of questionnaires to the respondents. They were informed to answer all items in the questionnaire and were assured of the confidentiality of the data gathered. All respondents were given two days duration to answers the questionnaire. The estimated average time taken by respondents to complete the questionnaire was approximately 7 minutes. After the deadline, the researchers collected back the questionnaire. Out of 45 questionnaires distributed, only 33 were returned to the researchers ( $94.3 \%$ return rate).

\section{Data Analysis Procedure}

To answer the first and second research questions, descriptive statistics such as mean, standard deviation, and percentage were used. The mean and standard deviation were calculated by using SPSS. Mean score below 1.66 was considered as low level, mean score between 1.67 to 3.32 was considered as medium level, and mean score above 3.33 was considered as high level.

As for the third and fourth research questions, a one-way analysis of variance (ANOVA) was used to determine whether there were statistically significant differences in perceived supervisory practices according to courses and frequency of meeting. Meanwhile, to answer the fifth research question, Pearson correlation test was used. The strength of the correlation index was determined based on the following table 1:

\section{Table 1}

Correlation Index

\begin{tabular}{cc}
\hline Index & Strength \\
\hline $\mathrm{r} \mid>0.8$ & Strong \\
$0.5<|\mathrm{r}|<0.8$ & Moderate \\
$|\mathrm{r}|<0.5$ & Weak \\
\hline
\end{tabular}




\section{RESULTS AND DISCUSSION}

\section{Perceived Supervisory Practices}

Research Question 1: What is the level of supervisees' perception towards the supervisory practices of their dissertation supervisor?

\section{Table 2}

Perceived Supervisory Practices

\begin{tabular}{lcccc}
\hline Perceived supervisory practices & N & Mean & SD & Level \\
\hline Safe Base & 33 & 4.11 & 0.696 & High \\
Structure & 33 & 3.69 & 0.527 & High \\
Commitment & 33 & 3.96 & 0.621 & High \\
Role-model & 33 & 4.10 & 0.545 & High \\
Feedback & 33 & 3.97 & 0.731 & High \\
\hline Total & 33 & 3.96 & 0.652 & High \\
\hline
\end{tabular}

Table 2 illustrates high level of perceived supervisory practices $(\mathrm{M}=3.96, \mathrm{SD}=.652)$. This means that most supervisees perceived that their dissertation supervisors have frequently applied various supervisory practices during the supervision sessions. Besides that, all the dimensions of supervisory practices that consist of safe base, structure, commitment, role model, and feedback also recorded high level (refer to Table 2). This finding further strengthens the overall findings of supervisory practice that indicate the supervisors in the faculty were not only frequently applied various supervisory practices, but also rotated the usage of each supervisory practice category from time to time without being over-dependent on one supervisory practice category only while conducting supervision.

Safe base dimension recorded the highest mean score $(\mathrm{M}=4.11, \mathrm{SD}=0.696)$. This means that most supervisees viewed that supervisors in the Faculty of Education have utilized supervisory practices under the safe base dimension in a very frequent manner. Most of the supervisors probably have succeeded in setting a good collaborative environment during the supervision in which they respect and value their supervisees' opinions as well as being supportive and responsive to supervisees' needs and problems. Furthermore, this finding is parallel with Lessing and Lessing's (2004) suggestion that equilibrium is essential between supervisor input and student independence during the consultation of postgraduate research works. Too much control and input by the supervisor will eventually lessen supervisees' critical thinking in conducting the research; whereas too much independence will cause the students to either produce substandard postgraduate research work or conduct impractical research that takes such a long time to be completed.

Meanwhile, structure dimension scored the lowest mean among all perceived supervisory practices $(\mathrm{M}=3.69, \mathrm{SD}=0.527)$. This means that most supervisees viewed that supervisors in the Faculty of Education have utilized supervisory practices under structure dimension the least when compared to the other four dimensions during supervision. Most of the supervisors probably are not very good in scheduling frequent meetings with supervisees as well as not very good in ensuring that the meetings are free from interruption. This is because lecturers cum 
supervisors have various tasks ranging from teaching, conducting research and innovation projects, as well as administrative to be accomplished. Hence, meetings are prone to be cut short due to external factors such as teaching duties and meetings with top management.

\section{Supervisees' Satisfaction}

Research Question 2: What is the level of satisfaction of the supervisees towards the supervision that they have received?

Table 3

Mean Scores of Supervisees' Satisfaction

\begin{tabular}{lllcc}
\hline & N & Mean & SD & Level \\
\hline Supervisee's satisfaction & 33 & 3.94 & 0.864 & High \\
\hline
\end{tabular}

Table 3 shows the overall satisfaction of the supervisees towards the supervision that they have received recorded a high level $(\mathrm{M}=3.94, \mathrm{SD}=.864)$. This result shows that majority of the supervisees were very satisfied with the supervision that they have received from their respective supervisors and the supervisors in the research have been doing a great job in assisting their supervisees to complete their dissertations.

\section{Perceived Supervisory Practices and Courses}

Research Question 3: Is there any significant difference between perceived supervisory practices and courses?

Table 4

One Way ANOVA of Perceived Supervisory Practices between Courses

\begin{tabular}{lcccccc}
\hline Courses & N & Mean & SD & Df & F & Sig. \\
\hline TESL & 8 & 3.89 & 0.588 & 2 & 0.217 & 0.806 \\
Management \& Leadership & 16 & 3.95 & 0.677 & 30 & & \\
Arts & 9 & 4.07 & 0.228 & & & \\
\hline Total & 33 & 3.97 & 0.497 & & & \\
\hline
\end{tabular}

To determine whether the mean scores are significantly different, a One-way ANOVA test was conducted. Table 4 reveals that there was no significant difference between perceived supervisory practices and courses, $\mathrm{F}(2,30)=0.217, \mathrm{p}=0.806>0.05$. This means that the supervisors for all courses in the Faculty of Education so far have applied high level of supervisory practices in the overall context and the five dimensions (refer to Table 4). Another reason why there was no significant difference between perceived supervisory practices and courses is probably due to the number of respondents for each course was very small $(<30)$. 


\section{Perceived Supervisory Practices and the Frequency of Meeting}

Research Question 4: Is there any significant difference between perceived supervisory /practices and the frequency of meetings?

\section{Table 5}

One Way ANOVA of Perceived Supervisory Practices between Frequency of Meeting

\begin{tabular}{lcccccc}
\hline Frequency of meetings & $\mathrm{N}$ & Mean & SD & df & F & Sig. \\
\hline Very frequent & 12 & 3.99 & 0.426 & 2 & 0.04 & 0.961 \\
Frequent & 11 & 3.98 & 0.568 & 30 & & \\
Not frequent & 10 & 3.93 & 0.715 & & & \\
\hline Total & 33 & 3.97 & 0.808 & & & \\
\hline
\end{tabular}

To determine whether the mean scores are significantly different, a One-way ANOVA test was conducted. Table 5 reveals that there was no significant difference between perceived supervisory practices and frequency of meeting; $\mathrm{F}(2,30)=0.04, \mathrm{p}=0.961>0.05$. This indicates that perceived supervisory practices in the research were not affected by how frequent or infrequent meeting that took place between both supervisors and supervisee. Hence, the findings of the overall perceived supervisory practices and the five dimensions (refer to Table 5) depicts the real supervision situation in the faculty at the time when the research was conducted.

\section{Perceived Supervisory Practices and Supervisees' Satisfaction}

Research Question 5: Is there any significant relationship between perceived supervisory practices and supervisees' satisfaction?

Table 6

Correlation between Perceived Supervisory Practices and Supervisees'Satisfaction

\begin{tabular}{llrr}
\hline & & $\begin{array}{r}\text { Perceived Supervisory } \\
\text { Practices }\end{array}$ & $\begin{array}{r}\text { Supervisees' } \\
\text { Satisfaction }\end{array}$ \\
\hline Perceived Supervisory & Pearson & 1 & $.827^{* *}$ \\
Practices & Correlation & & \\
& Sig. (2-tailed) & 57 & .000 \\
Supervisees' & N & $.827^{* *}$ & 57 \\
Satisfaction & Pearson & & 1 \\
& Correlation & .000 & \\
& Sig. (2-tailed) & 57 & 57 \\
\hline
\end{tabular}

Note. $* *$. Correlation is significant at the 0.01 level (2-tailed). 
Table 6 shows the result of Pearson Correlation Coefficient analysis between perceived supervisory practices and supervisees' satisfaction. The magnitude of the correlation was $r=$ 0.827 with $\mathrm{p}$-value $=0.00$. This shows a positive, strong, and significant relationship between the perceived supervisory practices and supervisees' satisfaction. Hence, this means that the higher the perceived supervisor practices, the higher the supervisees' satisfaction. By applying various supervisory practices, all needs of the supervisees will be able to be fulfilled and subsequently, this leads to their satisfaction. Hence, it is suggested to all postgraduate research supervisors to adopt various supervisory practices regularly during supervision to enhance supervisees' satisfaction as well as to maintain balanced dynamics in the supervisor-supervisee relationship.

\section{Factors that Affect Supervisee' Satisfaction}

Most respondents who rated 4 and 5 for their satisfaction towards the supervision that they have received stated that their supervisors were very understanding and continuously gave positive feedback to the supervisees. For example,

"My supervisor understands and gives positive feedback about my research”(Respondent 3)

"She always allocates time to read my dissertation progress, even though I send it through email" (Respondent 7)

"My supervisor is very understanding. She guides me regularly and is always concerned about my progress. Also, she treats me like her daughter which makes me feel appreciated." (Respondent 17)

"My supervisor is very helpful. She always gives constructive feedback and motivates me to finish my thesis to graduate on time" (Respondent 19)

"My supervisor continually motivates me to complete my research"

(Respondent 25)

Other than that, certain supervisees felt satisfied with the idea-sharing process that took place during the supervision session.

"She helps to find a new topic for my dissertation. She is also very understandable with my job. Although, she is very strict; yet I felt comfortable with her." (Respondent 13)

"My supervisor assists me a lot in my thesis progression. She always shares her ideas. " (Respondent 20)

"He openly discusses and accepts my ideas and even provides guidance on how to work on my ideas for the dissertation". (Respondent 8) 
"My supervisor is well-experienced in my area of study. He provides me with all the help where necessary. Plus, he is also easy to see, consult and always reply to my messages." (Respondent 27)

"My supervisor really helps me in refining my dissertation. She is very patient with my constant changes in constructing and finalising my research. My supervisor assists me with a lot of suggestions and recommendations for my dissertation." (Respondent 31)

Meanwhile, certain respondents who rated 1, 2, and 3 for their satisfaction towards the supervision that they have received stated that their supervisors were very busy and it was hard to meet for a consultation. For example,

"Hard to arrange an appointment as my supervisor is always busy". (Respondent 4)

"My supervisor is very busy. He tends to cancel our consultation last minute and always replies late to my e-mail and text messages” (Respondent 29)

\section{Recommendation of the Current Supervisor to Future Supervisees}

\section{Table 7}

Recommendation of Current Supervisors to Future Supervisees

\begin{tabular}{ccc}
\hline & Number of respondents & Percentage (\%) \\
\hline Yes & 26 & 78.8 \\
No & 7 & 21.2 \\
\hline & 33 & 100 \\
\hline
\end{tabular}

Table 7 shows that majority of the respondents (26 out of 33) agreed that they would like to recommend their current dissertation supervisor to future supervisees (78.8\%). Yet, 7 respondents disagreed and they would not like to recommend their current dissertation supervisor to future supervisees $(21.2 \%)$.

Findings revealed that the reasons or factors behind respondents' recommendation of their current supervisors to future supervisees are similar to the reasons or factors behind supervisees' satisfaction. For example, most supervisees who would like to recommend their current supervisor to future supervisees stated that it is due to the abundant ideas, wide research knowledge, and research experience of the supervisors.

"I would recommend this supervisor to future supervisee because he is knowledgeable and has vast experience in research.” (Respondent 6)

"She is a very good supervisor who can help you in your thesis progress with a lot of ideas and suggestion." (Respondent 14) 
She is very supportive and helps me to generate ideas and planning for the research." (Respondent 22)

Other than that, the responsive quality and availability of the supervisors play a crucial role in the respondents' nomination of the supervisors to future supervisees. For example:

He will reply to text messages/ Whatsapp immediately unless when he has urgent matters to be settled." (Respondent 3)

She will help her supervisees from time to time and gives fast feedback to help the students achieve GOT.” (Respondent 21)

"She is approachable and always makes time for her students. Plus, she trusts and appreciates her supervisees ' efforts.” (Respondent 33)

Conversely, supervisors who are busy and always unavailable for constant consultation were not recommended by respondents to be future supervisors of other students. For example,

"She has other commitments and it is hard to find her free time for a detailed supervision.” (Respondent 24)

\section{CONCLUSION AND RECOMMENDATION}

In conclusion, perceived supervisory practices and supervisees' satisfaction are related. Good supervisory practices definitely will increase supervisees' satisfaction, because all needs of the supervisees will be fulfilled. A good supervisor will also give constructive feedback and encouraging words from time to time which will boost supervisees' motivation and dedication to produce a good quality dissertation or thesis.

As for recommendations, the sample for this research is only 33 respondents. Therefore, future research can employ mixed methods and use bigger samples to gain in-depth analyses of the issue. Besides that, future research might also study these two variables of perceived supervisory practices and supervisees' satisfaction with other related variables such as supervisors' years of experience as researchers, supervisors' annual number of research publications, and supervisees' learning style. 


\section{REFERENCES}

Amzat, I.H., Yusuf, M., \& Kayodea,B.K. (2010). Quality research supervision in some Malaysian public universities: Supervisees' expectations and challenges. OIDA International Journal of Sustainable Development, 1 (5), 15-24.

Abiddin, N. Z., Ismail, A., \& Ismail, A. (2011). Effective supervisory approach in enhancing postgraduate research studies. International journal of humanities and social science, l(2), 206-217.

Athiyaman, A. (1997). Linking student satisfaction and service quality perceptions: the case of university education. European Journal of Marketing, 31(7), 528-540.

Chiappetta-Swanson, C., \& Watt, S. (2011). Good practice in the supervision \& mentoring of postgraduate students: It takes an academy to raise a scholar. Hamilton, Ontario: McMaster University.

Del Río, M. L., Díaz-Vázquez, R., \& Maside Sanfiz, J. M. (2017). Satisfaction with the supervision of undergraduate dissertations. Active Learning in Higher Education, 19(2), 159-172. doi:10.1177/1469787417721365

Dericks, G., Thompson, E., Roberts, M., \& Phua, F. (2019). Determinants of PhD student satisfaction: the roles of supervisor, department, and peer qualities. Assessment \& Evaluation in Higher Education, 1-16. doi:10.1080/02602938.2019.1570484

Ganqa, N. H. (2012). Research supervision experiences of masters in education students at a South African University. Doctoral dissertation, University of Fort Hare.

Ismail, A., Abiddin, N. Z., \& Hassan, A. (2011). Improving the development of postgraduates' research and supervision. International Education Studies, 4(1), 78-89

Kaur, S.K. \& Sidhu, G.K. (2019). A Qualitative Study of Postgraduate Students' Learning Experiences in Malaysia. International Education Studies, 2(3), 47-56.

Lessing, N., \& Lessing, A. C. (2004). The supervision of research for dissertations and theses. Acta Commercil, 4, 73-89.

Mohamad Tahir, I., Abdul Ghani, N., Engku Mamat, E.S. \& Abdul Manaf, Z. (2012). Effective supervision from research students' perspective. International Journal of Education, 4(2), 211-222.

Palomo, M., Beinart, H., \& Cooper, M. J. (2010). Development and validation of the Supervisory Relationship Questionnaire (SRQ) in UK trainee clinical psychologists. British Journal of Clinical Psychology, 49(2), 131-149.

Shuss, C. M. (2012). Supervisory Styles and Satisfaction: Genetic Counseling Student and Graduate View. Doctoral dissertation, Case Western Reserve University.

Wichmann-Hansen G., Bach L.W., Eika B., \& Mulvany M.J. (2012). Successful PhD supervision: A two-way process. In: Castanho M., Güner-Akdogan G. (eds) The Researching, Teaching, and Learning Triangle. Mentoring in Academia and Industry, Vol 10. Springer, New York, NY. Retrieved from https://doi.org/10.1007/978-1-4614-05689_5 